\title{
Contemporary Perception of Mental Health's Stigma in the Bay Area
}

\author{
John Pham ${ }^{1}$
}

${ }^{1}$ Santa Clara High School, Santa Clara, CA, USA

\begin{abstract}
Mental health is a common topic of discussion in our society today, especially in the Bay Area. What was once viewed as a taboo by many is now at the forefront of discussion and a high priority for both schools and workplaces. As a result of this change, there has been a drastic shift in public perception towards mental health and the stigma pertaining to it. There have been many studies that address the public's views on mental health but have failed to address the change towards the stigma of mental health today. In this study, I will be studying the contemporary perception of mental health combined with views of its stigma and public ideas on reducing this issue. The study consists of a thematic analysis of survey responses from a group of 45 respondents that were collected online through the site, Reddit, and other social media platforms. Responses were systematically sorted into separate themes to better group respondents' views and combine similar ideas in responses. The results of this study align with initial views and show an overall view from respondents that shows the Bay Area has undergone a reduction in the stigma and is implementing better methods of addressing these problems. This study increases the current body of knowledge regarding contemporary the Bay Area's citizens' views towards mental health and provides additional ways to reduce this stigma, allowing for more effective methods of counseling and mental health services in the near future.
\end{abstract}

\section{Introduction}

Everyone talks about mental health in our society today—but for good reason: there were estimated to be 46.6 million adults in the US with a mental health illness in 2017 (NIMH, 2017) representing almost $20 \%$ of the population. To put that in perspective, out of a group of five people you may know, at least one of them will have some sort of affiliation with mental health disorders firsthand. This number, however, only represents the adult population in the US. The rate of mental illness is just as severe in children as it is in adults. The National Institute of Mental Health (NIMH) has estimated that, similarly to adults, around one out of every five youth, ranging from the age of 13 to the age of 18, has experienced some type of serious mental health disorders. From anxiety disorders to depression, there is an array of mental health disorders that are seen in society today with the numbers only seeming to grow as years progress.

But even these estimates are far from the actual number affected. There is a wide population of people who are afraid to come for help addressing their issues. Many people avoid confronting their health problems due to the societal view of mental illness. The 46.6 million people that were estimated to be affected in the US in 2017 (NIMH, 2017) only represent a fraction of the total amount affected. A study conducted in 2013 by the World Health Organization had estimated that "nearly two-thirds of people with a known mental disorder never seek help from a health professional" citing stigma and public neglect as the main reasons for lack of support (WHO, 2013). These numbers show how significant a problem mental health disorders are in our world today and put into perspective how common these problems are. 


\section{Definitions}

Before continuing, however, there is a word that will need to be clarified in order to effectively convey the ideas and key terms behind some previous studies. In this study, the word "stigma" will be referenced multiple times and refers to the disapproval that some associate with maintaining one's mental health. In other words, it is a negative connotation that is associated with the idea of mental health disorders. Understanding what stigma means in this context can help provide better visualization of the previous studies and highlight the goals of this study.

\section{Cornerstone Work on Topic in Field}

The state of California has tried its share of efforts to reduce this stigma with the most notable effort seen in 2004. In that year, voters approved the Mental Health Services Act, with the goal of addressing mental health's public perception. The bill implemented over 25 new projects aimed at reducing stigma and discrimination at multiple levels of society. From institutions to societal norms, it planned on fostering permanent change in the public's view of mental health and work towards positive perceptions on mental health illnesses.

As a result of these changes, many studies have decided to revisit Proposition 63 in the last decade. These more recent studies aimed at locating the effects of this proposition and if there has been a change in perception towards mental health and its stigma. One of the studies, conducted by researchers Rebecca Collins, Jennifer Cerully, Eunice Wong, Shari Golan, Jennifer Yu, and Gabrielle Filip-Crawford, analyzed the current public perception towards mental health. Through their study, they concluded that although these methods have been useful in reducing the stigma, it still persists to somewhat of a high degree in society today. As time progresses, however, they predict that the creation of new programs from the proposition will help continue reducing the stigma and hopefully fully eradicate the stigma associated with mental health.

Yet, in order to effectively address the problem of stigmatizing mental health, many researchers have taken other factors into account. Factors such as culture and socio-economic status have been linked to mental health's stigmatization. A recent study, conducted by Narayan Gopalkrishnan in 2018, found convincing evidence that strengthens the idea that there is a link between one's cultural diversity and mental health. Gopalkrism specifically notes, "the differences in cultures have a range of implications for mental health practice, ranging from the ways that people view health and illness, to treatment seeking patterns, the nature of the therapeutic relationship and issues of racism and discrimination." (Gopalkrism, 2018). It is evident that a general method of combating stigma associated with mental health will not be as effective as individualized plans.

Health providers need to take these factors into account and tailor their assistance to each individual patient. The views of stigma and mental health vary widely from culture to culture and with different factors. If healthcare providers are able to get a better understanding of specific issues, the problem of stigma will alleviate over time. Understanding the specific factors pertaining to different groups of individuals can help mental health providers establish new methods of combating these issues within these specific communities and result in more effective treatments.

\section{Arguments on Topic in the Field}

Aside from the previous studies, there have been additional studies conducted recently that somewhat focus on the perspective of the general population and aim to gain a better understanding of this issue through different lenses. There was a study conducted at UCSF that found that there was some self-stigma that patients associated with their own mental health (UCSF, 2016). Researchers in this study noted that this self-stigma resulted in patients distancing themselves from others and society. They also noticed the lack and shortage of these mental health services available throughout the US aimed at combating these illnesses. 
Although more Americans are becoming more knowledgeable in the field of mental health, there is still a severe shortage of mental health services and a lack of action from the public regarding this issue. Researchers at UCSF had come to the conclusion that ending the stigmatization of mental health required additional long-term efforts by the state and multiple policy changes. This stigma is still prevalent in society today, and there needs to be more programs or policies developed that address this issue.

\section{Gaps Regarding Mental Health}

There has been a lack of studies in the last few years directly pertaining to mental health's perception from the public, specifically towards its stigmatization. While many researchers have conducted their own studies pertaining to mental health, they have failed to delve deeper into ideas pertaining to mental health's stigmatization and specialize in specific communities.

There have been, however, a few studies that have integrated some aspects of stigma into their study. The most recent studies were conducted by researchers at UCLA and the Michigan Sociological Review in 2018 and 2016 respectively. More specifically, these studies at UCLA and the Michigan Sociological Review had focused on stigma's effect on college students throughout the US. In these studies, the scale for stigma was determined by questions where participants would answer through a sliding scale. Participants would answer from a scale of one to ten regarding how closely the statement provided aligned with their behavior and beliefs. Some questions include "whether they would accept someone as a friend, or think less of someone if they knew that person had been treated for mental illness" and "a battery of questions to determine if they had anxiety or depression and revealed whether they had suicidal thoughts or committed intentional self-harm." (UCLA, 2018). Through their research, they had noted that students at their selected college were less likely to go for help if the associated stigma was higher.

Although these studies were collected in areas somewhat close to the Bay Area and focused on collecting data regarding the perception of mental health's stigmatization, they are limited in that they had only collected data from college students. There is still a major gap in knowledge pertaining to the general publics' thoughts and perception of this stigma in 2020. These studies, however, will provide some additional background and data that may be able to be used as a comparison to that of my study.

\section{Hypothesis}

The last few years have seen a radical shift in the public's perception of mental health. The public's perception of mental health has undergone a tremendous change. Fortunately for us, what was once considered synonymous with taboo has been brought to the forefront of the discussion today. Multiple schools, companies, and corporations in the Bay Area have implemented their own ways of maintaining mental health. The stigma associated with mental health has alleviated over time and I want to gauge this change and see what the perspective of the Bay Area is today.

\section{Assumptions}

However, there are some assumptions made in this study in order to effectively address the research question. In this study, I am assuming that the public has somewhat of an understanding of what mental health illnesses are and what stigma refers to in this particular discipline. Without some background knowledge in this field, the responses won't accurately reflect the participants' beliefs and provide inaccurate data. Aside from the previous assumption, there is also the assumption that the population of interest is providing me with unbiased and truthful answers to the questions that they have been given. 


\section{Research Statement}

Following this background research, I decided to conduct a study based on the question: How has the changing views on the stigmatization of mental health disorders influenced the perception of mental health for adults in the Bay Area today? In my study, I will undergo an analysis of the correlation between the new perspectives on mental health stigma and its effect on changing the public's view of mental health today. I want to gain a comprehensive view of the perception of the Bay Area towards the stigma associated with mental health. With the data, there will be a better understanding of contemporary societal beliefs of mental illness and its stigma to health care providers and the public.

\section{Methods}

In this research, I collected information regarding one's perception of mental health in the Bay Area. I asked the general public 12 questions regarding the stigma associated with mental health and their own perceptions of mental health. All of the research subjects had received an exempt consent form that briefly outlines the survey and my contact information. Each survey should have taken approximately 15 minutes to complete and all participants had the ability to exit the survey at any time.

For my research, I had distributed my survey to various online forums that host a high population of users who are from the Bay Area. I had sorted through the online website, Reddit, since it was the main location that I focused on sending surveys through. By using this platform, I was able to then sort through the "subreddits", otherwise known as the smaller forums, and find the ones that had my population of interest. A sample Reddit post that was created to send out surveys can be found in Appendix A. Additionally, the full survey that was distributed can be found in Appendix B, which includes the exempt consent form as well as all the questions provided to participants.

After the surveys were sent out, I made sure to monitor the survey to see the number of respondents. The methods used in this research study have been carefully selected to provide a broad sample and a range of views pertaining to mental health. Participants were able to respond with anonymity and provide truthful responses to the questions given. It allowed me the ability to get an overall understanding of my respondents' perception and thus a view representative of the Bay Area.

\section{Sample Questions from Survey Distributed}

- Is there anything that you would want to see implemented at schools to help students deal with mental health?

- Should schools and workplaces place emphasis on maintaining one's mental health?

- Would you consider going to a therapist if you were struggling with your mental health?

- Do you think that there is a negative stigma associated with one's mental health and mental disorders in general? (Note: Stigma refers to a mark of disgrace associated with a particular circumstance, quality, or person)

Once the surveys were completed, I went through all of the raw responses and sorted the data collected into different groups pertaining to common themes that I had developed. Using thematic analysis, each individual question and its responses were coded to separate subgroups with a corresponding theme. Once the responses were categorized and undergone a thorough analysis, I was able to then create the appropriate conclusions to my question based on the frequency of each theme's appearances in participant responses.

However, I foresaw multiple problems with my survey before distributing that unfortunately occurred. The main problem that I faced was nonresponse as this type of research is notorious for its low return rate for responses. This had restricted the sample size that I was able to collect. Other roadblocks to this study pertain to protected groups. As a result of sending these surveys out blindly online, I faced the problem of inevitably sending a survey to an 
individual classified in a protected group. However, I had worked to the best of my ability to create the online questionnaire using specific wording and refined the introductory section to sort out individuals in these protected groups and prevent them from participating in the survey. However, it is possible that it wasn't sufficient and needed additional information added to ensure that my survey didn't reach the hands of those in protected groups.

The final problem that could have occurred in my research pertains to the actual questions on the survey. As I am not able to edit the survey once it is sent out, I had a very limited effect on the respondents' interpretations of the questions. Participants may have misinterpreted questions and respond with biases in their answers which had the ability to limit the amount of usable information that is collected. I made sure to edit the questions to maintain a neutral tone and avoid bias, improving question clarity before the surveys were sent out.

\section{Initial Perceptions of Mental Health and Stigma}

Before going into the actual participants' written responses, participants were asked to answer some general questions regarding their general perceptions of stigma. This will provide some general information to work off when analyzing the written responses to questions pertaining to mental health stigma.

Initially, participants were asked to identify which of the following mental health disorders that they had experienced with or had heard of. There was also the option to input additional mental health disorders if they were not already listed as an option. Which of the following do you have experience with or know? Mark all that apply
19 responses

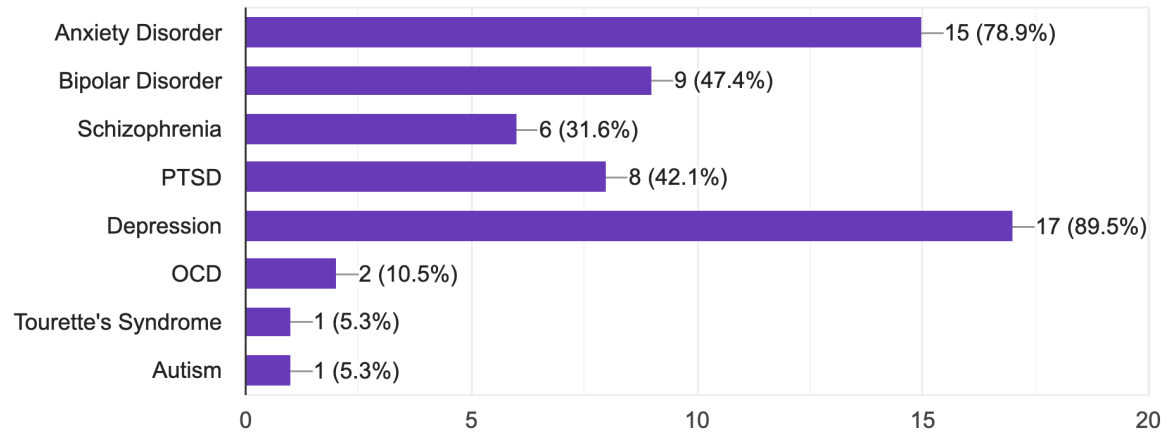

Figure 1. Breakdown of responses to the question asked to the participants to identify which of the following mental health disorders that they had experienced with or had heard of.

Out of the five mental health disorders listed, Depression was the most well-versed and known mental health disorder with Anxiety being the second most well-known. It is important to note that a few participants had added OCD, Tourette's, and Autism as other known mental illnesses/disorders that they had experience with.

Following this question, participants were asked another question regarding their general view of stigma on mental health. Participants were given three answer choices: "Yes, there's a stigma associated with mental health disorders", "No, there's no stigma with mental disorders", and "I'm not sure". 


\begin{abstract}
Do you think that there is a negative stigma associated with one's mental health and mental disorders in general? (Note: Stigma refers to a mar...with a particular circumstance, quality, or person) 20 responses
\end{abstract}

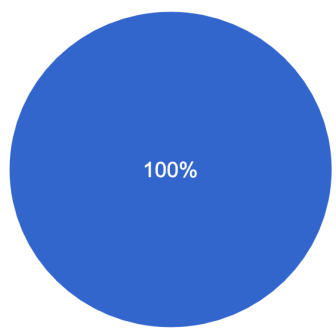

Yes, there's a stigma associated with mental disorders

No, there's no stigma with mental disorders

I'm not sure

Figure 2. Breakdown of responses to the question asked to the participants regarding their general view of stigma on mental health.

All participants had acknowledged that there was indeed a stigma associated with mental health. This can be interpreted towards the overall Bay Area's perception as all respondents to these questions were sorted out to consist of only California residents. They also all agreed with the general definition of "stigma" that was provided. The following two questions pertained to combatting mental health issues and how these issues are addressed in society today. Participants were asked if the stigma associated with mental health prevented people from getting help and if they would look to counseling or therapy if they were facing problems with their mental health

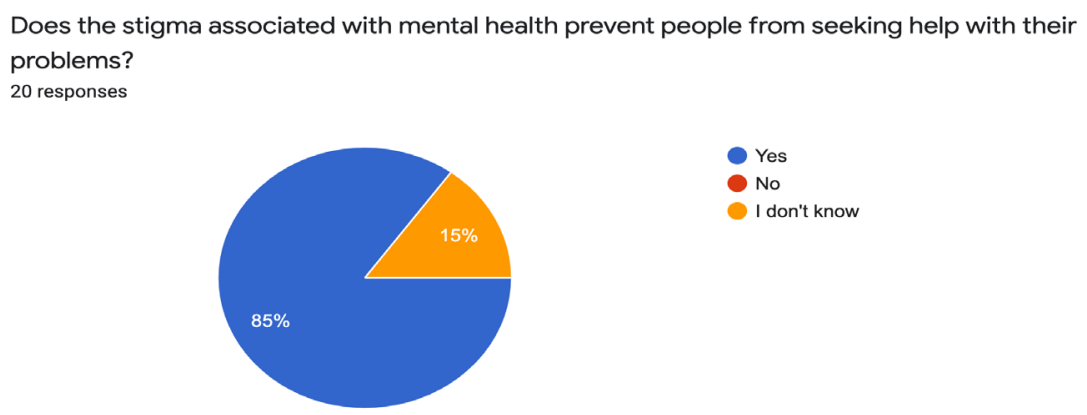

Figure 3. Breakdown of responses to the question regarding stigma associated with mental health.

Would you consider going to a therapist if you were struggling with your mental health? 20 responses
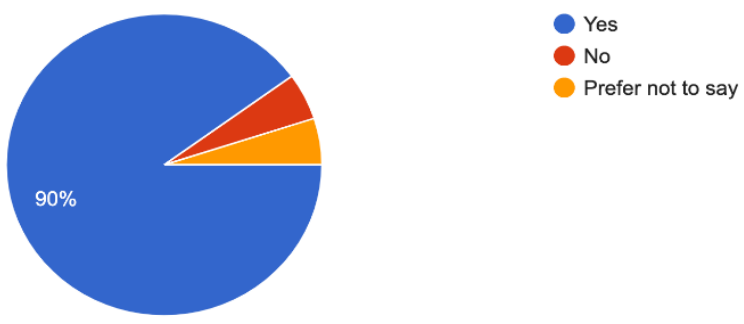

Figure 4. Breakdown of responses to the question regarding seeing a therapist if the participants were struggling with their mental health. 
The majority of the respondents said that they would consider therapy if they were struggling with their overall mental health. Connecting the previous question to this response, we can note that while the respondents believed that stigma would inhibit others from getting help, they were all open to getting help with their problems if necessary.

To conclude this section, participants were provided with another question pertaining to how society is currently addressing mental health issues, specifically for schools and workplaces.

\title{
Should schools and workplaces place emphasis on maintaining one's mental health?
}

20 responses

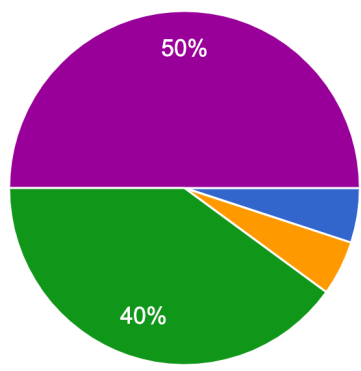

\author{
Strongly disagree \\ Disagree \\ Neutral \\ Agree \\ Strongly agree
}

Figure 5. Breakdown of the responses to the question regarding emphasis of mental health at the schools/workplaces.

This question had mixed responses about school efforts towards student mental health and company efforts towards worker mental health. However, there was an overall agreement with one side of the scale. Many respondents leaned towards agreeing on increased support for mental health with few respondents disagreeing overall with this statement.

\section{Perception of Societal Efforts to Aid Mental Health}

Following this section, participants were asked to provide a number representing their perceptions of mental health today. A score of ten would have meant high importance to the respondent while a score of one would have meant that there was no importance to the respondent.
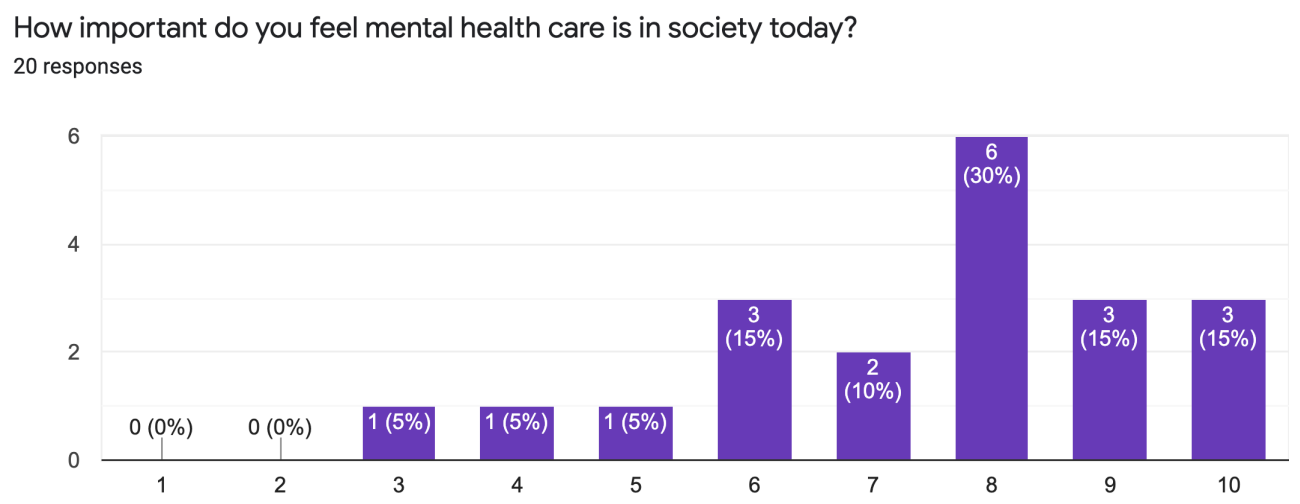

Figure 6. Breakdown of responses to the question regarding how the mental health care is in society today.

Participants generally placed mental health care as having high value in society today. On a scale of one to ten, the average score was 7.45 with the median score at 8 . This can be interpreted as contemporary beliefs favoring self-care and mental health. 
When asked a similar question pertaining to the general amount of people that they believed to be affected by mental health disorders, respondents responded with scores similar to that of the previous question.

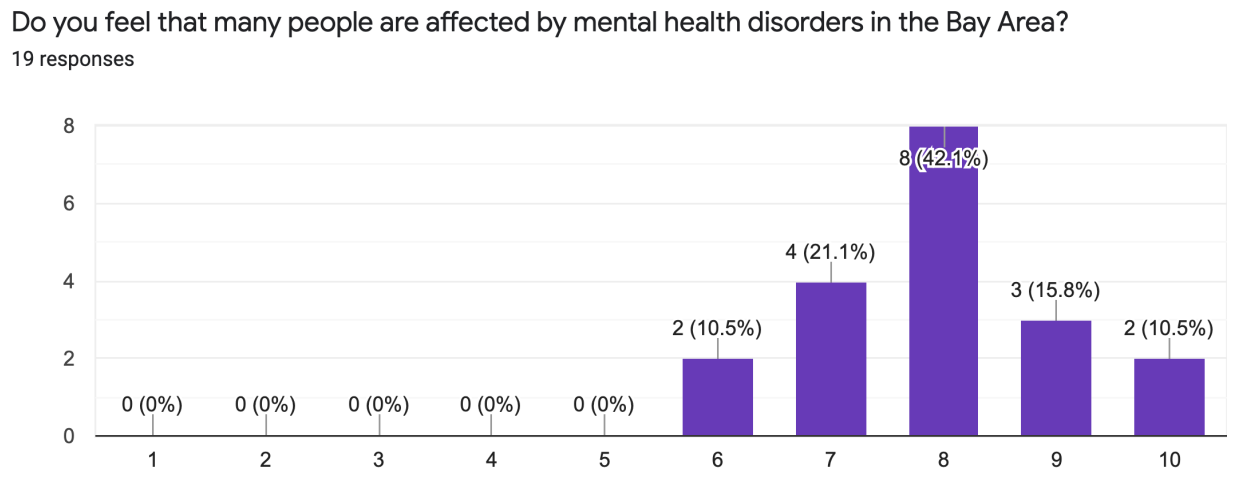

Figure 7. Distribution of how participants were affected by mental health disorders in the Bay Area.

The average score was 7.95 with a median of 8 . Comparing this graph with the graph about mental health's importance in society today, we can note that the question responses are aligned together. We can hypothesize that respondents believed that many people were/are facing mental health issues which increases the importance of mental health. The greater the population perceived to be affected by mental health disorders, the respondents would rank mental health's importance higher in accordance.

To conclude the section pertaining to the initial perception of mental health and its stigmas, participants were asked to rate society's effectiveness in reducing the stigmatization of mental health.

How effective has society been in reducing this stigma?

20 responses

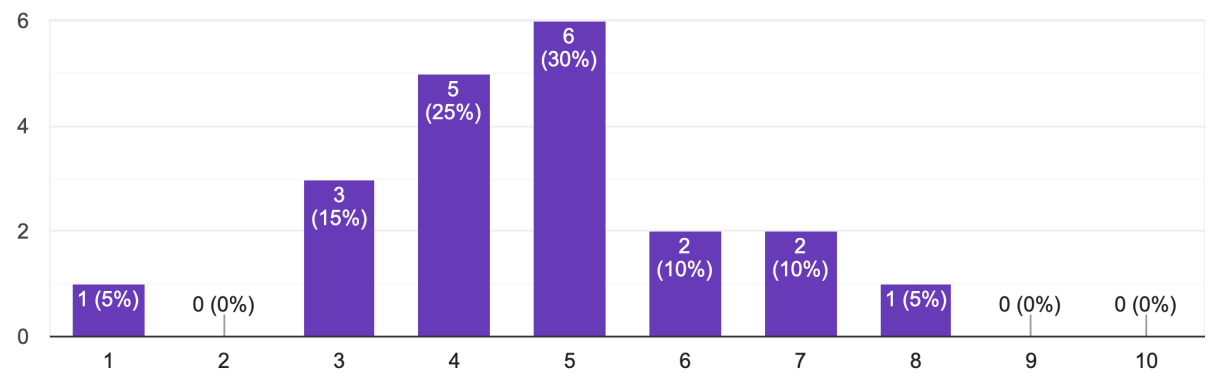

Figure 8. Distribution of the responses regarding how effective the society had been in reducing the stigma associated with the mental health care.

Participants provided scores to this question that were on the lower end of the spectrum. The average rating was 4.7 with the median at 5 . While participants generally felt that a high proportion of people were and are affected by mental health disorders, they had also believed that society had inadequately addressed these problems. Placing mental health at a high priority is a common theme in these responses. It is quite plausible that there has been a tremendous shift in view from the public on these issues as seen through these initial questions provided. 


\section{Participant Written Responses/Perspectives}

The final section of the survey distributed asked participants to create written responses to the questions provided based on their beliefs as of now. Participants were urged to provide true responses that were unbiased and representative of their beliefs.

Participants' responses to the written questions have been categorized below. Out of the 44 respondents total, there are a total of 13 responses that adhere to the constraints of the survey. Those 13 responses have been categorized on Table A. Names and background info for each participant has been removed to protect their identity. Each participant is referenced to as a number based on the order that they responded to the survey and each row represents the participants' responses to a specific question. For questions that participants did not answer or didn't answer properly, their response to that question has been marked as "Not Applicable".

Table 1. Responses to the Questions.

\begin{tabular}{|c|c|c|c|}
\hline $\begin{array}{c}\text { Participant \# } \\
\text { Note: Some numbers } \\
\text { have been omitted } \\
\text { due to non-response } \\
\text { and response re- } \\
\text { strictions }\end{array}$ & $\begin{array}{l}\text { Is there anything that you } \\
\text { would want to see implemented } \\
\text { at schools to help students deal } \\
\text { with mental health? }\end{array}$ & $\begin{array}{l}\text { What are your initial } \\
\text { thoughts on mental health } \\
\text { in the Bay Area? Feel free } \\
\text { to address the contempo- } \\
\text { rary perception of mental } \\
\text { health disorders and cur- } \\
\text { rent work environments. }\end{array}$ & $\begin{array}{l}\text { What do you think is con- } \\
\text { tributing to the increased } \\
\text { rate of mental health disor- } \\
\text { ders in the general public? }\end{array}$ \\
\hline 2 & $\begin{array}{l}\text { Encourage children to use } \\
\text { counseling and work to make } \\
\text { counseling more available. }\end{array}$ & $\begin{array}{l}\text { A lot of schools in the bay } \\
\text { area are highly competi- } \\
\text { tive (good schools, parents } \\
\text { wanting their children to } \\
\text { be successful), which cre- } \\
\text { ates more situations for } \\
\text { mental health problems to } \\
\text { occur. }\end{array}$ & $\begin{array}{l}\text { I don't think there is any } \\
\text { more mental health disor- } \\
\text { ders (though using the } \\
\text { word disorder creates } \\
\text { stigma), we just are learn- } \\
\text { ing more about them. }\end{array}$ \\
\hline 6 & $\begin{array}{l}\text { Better counseling, more access } \\
\text { to resources, and normalizing } \\
\text { use of these mental health re- } \\
\text { sources }\end{array}$ & $\begin{array}{l}\text { The Bay Area is becoming } \\
\text { increasingly stressful and } \\
\text { competitive, feeding into } \\
\text { mental health conditions. } \\
\text { The culture prioritizes } \\
\text { working hard overtaking } \\
\text { breaks and seeking help } \\
\text { for mental health issues. }\end{array}$ & $\begin{array}{l}\text { Society is becoming very } \\
\text { competitive, making life } \\
\text { more stressful for most. }\end{array}$ \\
\hline 11 & Education to decrease stigma & Not Applicable & Not Applicable \\
\hline 12 & $\begin{array}{l}\text { anonymous discussion services } \\
\text { for students }\end{array}$ & $\begin{array}{l}\text { extremely pressurized }+ \\
\text { competitive environment } \\
\text { for students --> stress }+ \\
\text { constant internal compari- } \\
\text { sons to people around you }\end{array}$ & $\begin{array}{l}\text { competitive atmosphere, } \\
\text { feeling of watching every- } \\
\text { body else succeed while } \\
\text { you stagnate }\end{array}$ \\
\hline
\end{tabular}




\begin{tabular}{|c|c|c|c|}
\hline 14 & $\begin{array}{l}\text { Just a streamlined way to get } \\
\text { adequate access to a thera- } \\
\text { pist/other professional for men- } \\
\text { tal health. }\end{array}$ & $\begin{array}{l}\text { Too much pressure on stu- } \\
\text { dents. Employees at tech } \\
\text { companies are overworked } \\
\text { (Example: Facebook em- } \\
\text { ployee who committed su- } \\
\text { icide last year). }\end{array}$ & $\begin{array}{l}\text { I think society is placing } \\
\text { more value on moving up } \\
\text { the social ladder and suc- } \\
\text { cess. }\end{array}$ \\
\hline 19 & Yes & $\begin{array}{l}\text { The Bay Area puts so } \\
\text { much pressure on being } \\
\text { perfect. It puts so much } \\
\text { pressure on being the ideal }\end{array}$ & $\begin{array}{l}\text { The lack of addressing the } \\
\text { problem }\end{array}$ \\
\hline 20 & Not Applicable & $\begin{array}{l}\text { I think mental health in the } \\
\text { Bay Area is a common is- } \\
\text { sue, and it's actually being } \\
\text { well-addressed compared } \\
\text { to other places across the } \\
\text { country, but the perception } \\
\text { of it and how it is being in- } \\
\text { formed can still improve. }\end{array}$ & $\begin{array}{l}\text { I think that people are just } \\
\text { becoming more self-aware } \\
\text { and being diagnosed for } \\
\text { their illnesses. }\end{array}$ \\
\hline 21 & Not Applicable & $\begin{array}{l}\text { Some people don't reach } \\
\text { out for help because they } \\
\text { either can't make time for } \\
\text { it, they can't afford it, or in } \\
\text { some cases, people don't } \\
\text { even realize they have a } \\
\text { mental health disorder }\end{array}$ & Not Applicable \\
\hline 22 & Mental health centers & $\begin{array}{l}\text { There's not enough time } \\
\text { for people to relax because } \\
\text { the Bay Area is an expen- } \\
\text { sive place to live in. }\end{array}$ & Smoking, drinking \\
\hline 23 & $\begin{array}{l}\text { All schools should have an eas- } \\
\text { ily accessible Wellness Center } \\
\text { (similar to the one we have at } \\
\text { ) }\end{array}$ & $\begin{array}{l}\text { Although many do not ad- } \\
\text { mit it, there is still a nega- } \\
\text { tive perception of mental } \\
\text { disorders in the Bay Area. }\end{array}$ & $\begin{array}{l}\text { Stress from work and } \\
\text { school. }\end{array}$ \\
\hline 24 & $\begin{array}{l}\text { Facilities that had emotional } \\
\text { check-ins with students, and fa- } \\
\text { cility members who kept an eye } \\
\text { out within classes to monitor } \\
\text { external emotional status occa- } \\
\text { sionally }\end{array}$ & $\begin{array}{l}\text { In the Bay Area, the over- } \\
\text { whelming competitive } \\
\text { spirit has led to increases } \\
\text { in the prevalence of mental } \\
\text { health issues within, likely } \\
\text { more so than other re- } \\
\text { gions. }\end{array}$ & $\begin{array}{l}\text { Increased stress and a very } \\
\text { challenging academic and } \\
\text { workforce environment. }\end{array}$ \\
\hline 26 & $\begin{array}{l}\text { Psychological counseling, rou- } \\
\text { tine screening. }\end{array}$ & $\begin{array}{l}\text { There is a lot of hostility } \\
\text { and negativity. }\end{array}$ & $\begin{array}{l}\text { Better awareness and eas- } \\
\text { ier access to care. }\end{array}$ \\
\hline
\end{tabular}




\begin{tabular}{|l|l|l|l|}
\hline & $\begin{array}{l}\text { More access to counselors. At } \\
\text { my high school, there were 2 } \\
\text { for 2400 students. Mental } \\
\text { health ed worked into a curricu- } \\
\text { lum similar to sex ed (among } \\
\text { other things I'd throw into a } \\
\text { class called "life skills") }\end{array}$ & $\begin{array}{l}\text { I think because the bay is } \\
\text { so connected (to the inter- } \\
\text { net), it's probably a much } \\
\text { lower stigma than in many } \\
\text { other places, simply be- } \\
\text { cause of increased expo- } \\
\text { sure to destigmatizing } \\
\text { ideas. However, I do think } \\
\text { that the environment can } \\
\text { be fairly high pressure, } \\
\text { which can lead to more } \\
\text { mental health problems. }\end{array}$ & $\begin{array}{l}\text { Largely increased diagno- } \\
\text { ses simply because more } \\
\text { people are seeking help } \\
\text { and we know more and are } \\
\text { more capable of diagnos- } \\
\text { ing (so, an observation } \\
\text { bias rather than more peo- } \\
\text { ple actually having disor- } \\
\text { ders). That being said, I } \\
\text { think there are many men- } \\
\text { tal illnesses that are dis- } \\
\text { eases of affluence, so are } \\
\text { increasing as society be- } \\
\text { comes wealthier. }\end{array}$ \\
\hline
\end{tabular}

\section{Common Themes in Responses/Opinions}

Table 2. Question 1: Is there anything that you would want to see implemented at schools to help students deal with mental health?

\begin{tabular}{|l|l|l|}
\hline \multicolumn{1}{|c|}{ Theme } & $\begin{array}{c}\text { Responses Discussing } \\
\text { Theme }\end{array}$ & \multicolumn{1}{|c|}{ Definition } \\
\hline $\begin{array}{l}\text { Better Counselling Services/More } \\
\text { Access to Counselors }\end{array}$ & $\begin{array}{l}2,6,14,22,23,24, \text { and } \\
30\end{array}$ & $\begin{array}{l}\text { Improvement of counseling services imple- } \\
\text { mented in schools in the Bay Area. Examples } \\
\text { could include new resources, additional coun- } \\
\text { selors, free access to a therapist, and more flex- } \\
\text { ible hours for appointments }\end{array}$ \\
\hline Education & 11 & $\begin{array}{l}\text { Increasing education about mental health. Im- } \\
\text { plementing a class or course that helps students } \\
\text { better understand the need to maintain their } \\
\text { mental health. }\end{array}$ \\
\hline Routine Check-ins & 12,26 & $\begin{array}{l}\text { Weekly/Monthly mandatory appointments } \\
\text { with counselors or therapists to help see where } \\
\text { students are mentally and their overall health. }\end{array}$ \\
\hline
\end{tabular}

Most Common Theme: Better Counselling Services/More Access to Counselors 
Table 3. Question 2: What are your initial thoughts on mental health in the Bay Area? Feel free to address the contemporary perception of mental health disorders and current work environments.

\begin{tabular}{|l|l|l|}
\hline \multicolumn{1}{|c|}{ Theme } & $\begin{array}{c}\text { Responses Discussing } \\
\text { Theme }\end{array}$ & \multicolumn{1}{|c|}{ Definition } \\
\hline $\begin{array}{l}\text { High-Pressure/Competitive Envi- } \\
\text { ronment }\end{array}$ & $2,6,12,14$, and 19 & $\begin{array}{l}\text { A societal belief that promotes toxic work- } \\
\text { places where employees are forced to compete } \\
\text { with their co-workers and outperform them. } \\
\text { Similar aspects of students in high school and } \\
\text { post-secondary. }\end{array}$ \\
\hline $\begin{array}{l}\text { Negative Perception of Mental } \\
\text { Health from Society }\end{array}$ & $20,21,23,26$ & $\begin{array}{l}\text { Associating the idea of mental health with a } \\
\text { negative connotation and having low urgency } \\
\text { to address the problem from the public's per- } \\
\text { ception }\end{array}$ \\
\hline Increased Connectivity & 30 & $\begin{array}{l}\text { Access to technology that allows the world to } \\
\text { become interconnected resulting in increased } \\
\text { exposure that destigmatizes the ideas pertaining } \\
\text { to mental health. }\end{array}$ \\
\hline
\end{tabular}

Most Common Theme: High Pressure/Competitive Environment 
Table 4. Question 3: What do you think is contributing to the increased rate of mental health disorders in the general public?

\begin{tabular}{|l|l|l|}
\hline \multicolumn{1}{|c|}{ Theme } & \multicolumn{1}{c|}{$\begin{array}{c}\text { Responses Discussing } \\
\text { Theme }\end{array}$} & \multicolumn{1}{c|}{ Definition } \\
\hline $\begin{array}{l}\text { High-Pressure/Competitive Envi- } \\
\text { ronment }\end{array}$ & $6,12,14,23$, and 24 & $\begin{array}{l}\text { A societal belief that promotes toxic work- } \\
\text { places where employees are forced to compete } \\
\text { with their co-workers and outperform them. } \\
\text { Similar aspects of students in high school and } \\
\text { post-secondary. }\end{array}$ \\
\hline $\begin{array}{l}\text { Increased Population Seeking } \\
\text { Help/Self Diagnosis }\end{array}$ & 20,25, and 30 & $\begin{array}{l}\text { Increased rate of mental health disorders is a } \\
\text { result of more people seeking the help they } \\
\text { need. The percent of the population that is af- } \\
\text { fected may not have changed, but more people } \\
\text { are now opened to asking for help. }\end{array}$ \\
\hline $\begin{array}{l}\text { Society's Lack of Addressing } \\
\text { Mental Health Issues }\end{array}$ & 19 & $\begin{array}{l}\text { Inadequate programs and policies that aimed to } \\
\text { reduce mental health issues in the general pub- } \\
\text { lic. }\end{array}$ \\
\hline
\end{tabular}

\section{Most Common Theme: High Pressure/Competitive Environment}

\section{Limitations to Research}

Before proceeding to the analysis of this data, it is important to note some of the limitations that were encountered through the course of this study. One of the main limitations was the participation rate. The problem of high rates of nonresponse made it difficult to collect an adequate sample size. This coupled with the problem of some participants being unable to respond to questions due to some criteria not being met had severely limited the amount of responses I received.

The survey had been posted through Reddit and its various sub-forums. More specifically, the forums r/SampleSize, r/ApplyingToCollege, $r$ /Teenagers, and r/APStudents had posts pertaining to the survey. These forums have upwards of 2,000 all the way to 40,000 members active at a time and are generally known for their responses to user posts. However, only a small proportion takes the time to fill out the survey. My survey was created to sort out respondents to keep only those who meet the criteria. While 46 people responded to the survey, approximately a third produced viable results worth analyzing and results that were usable.

\section{Analysis of Results}

Through the results collected from the surveys, each participant outlined their general thoughts on the stigmatization of mental health and provided their own perspective on how to reduce the stigma. These responses were then categorized by question and then further separated by additional themes. The raw data regarding each participants' response can be found on Table A, while the themes for each question can be found in Tables B through D.

This section, however, will dive deeper into analyzing the data and break down the participants' responses into groups of similar themes. By doing this, it will be easier to identify common ideas and beliefs in the participants 
and create a contemporary view of the stigmatization of mental health in the Bay Area for all three written response questions.

I was able to create a total of eight distinct themes that were created as a result of the responses. Out of these eight themes, it is important to analyze the frequency in which they appear in participants' responses. Analyzing the frequency of each theme will allow us to create a picture of contemporary beliefs towards mental health. The frequency of each theme can be seen on Table B through D, with frequencies on Column 2. Through this analysis, we can conclude that there were three themes that stood out from the eight referenced.

\section{Recurring Theme 1 - Better Counseling Services/More Access to Counselors}

(Number of Responses Aligning to Theme: 7)

This theme applies mainly to Question 1 but can be seen in some responses for the remaining two questions. Out of the three most prominent themes to Question 1's responses, the majority of participants believed that it was important to increase the opportunities for students to meet with a counselor. They felt that having a professional in the field of therapy and counselling would help to reduce the issues of mental health issues/disorders in students. For example, participant 24 had written that they would like to see:

"Facilities that had emotional check-ins with students, and facility members who kept an eye out within classes to monitor external emotional status occasionally"

Essentially, they are stating their belief that routine check-ups should be implemented in schools to help prevent students from encountering mental health issues, rather than having to treat these issues later. Similar responses came from other participants. Both participants 30 and 23 wanted increased accessibility to counseling services and mental health professionals. These responses suggest that these participants felt that there is an inadequate distribution of services allocated towards mental health in schools. This idea, however, can also be extended outside of the classroom environment as participants had also agreed that they would take advantage of these services, whether it be at school or outside of school.

\section{Recurring Theme 2 - High-Pressure/Competitive Environment}

(Number of Responses Aligning to Theme: 6)

This theme applies to Question 2 and 3. This theme combined two common responses together under an overall topic. Common topics of discussion under this theme included pressure in an academic atmosphere (secondary and postsecondary education) and pressure in the workplace. Majority of the respondents to this question had agreed that they felt an inherent pressure from society to perform to the best of their ability and work towards the top. This idea can be seen in Participant 6 who stated,

'The Bay Area is becoming increasingly stressful and competitive, feeding into mental health conditions. The culture prioritizes working hard overtaking breaks and seeking help for mental health issues."

Participant 21's response had built upon this common idea by noting that "some people don't reach out for help because they either can't make time for it, they can't afford it, or in some cases, people don't even realize they have a mental health disorder" which is a direct result of this toxic atmosphere and general state of society today. 
Similar responses were seen in participants 2, 12,14 and 19 for Question 2. Many respondents had also noted that this competitive atmosphere had promoted hostilities from many of their peers and coworkers. All of the factors that contributed to the high-pressure and competitive environments had also resulted in the deterioration of the mental health for many and increased the number affected by these illnesses. This can be seen in Participant 2's response where they noted that,

"A lot of schools in the Bay Area are highly competitive (good schools, parents wanting their children to be successful), which creates more situations for mental health problems to occur."

Participants also answered Question 3 with similar responses to Question 2. Many felt that the competitiveness of school and work had led to increased rates of mental health disorders in the public. They agreed that the pressure placed on success had led to many workers and students sacrificing their mental health for short-term success. Many had provided personal anecdotes towards increases in mental health disorder occurrences. Participant 11 felt that the "feeling of watching everybody else succeed while you stagnate" placed a large role in increases in mental health disorders. Their experience may have played an integral role in developing their line of reasoning for issues regarding mental health. Similarly, Participant 23 noted "stress from work and school" as another factor to increasing prominence of mental health disorders in the Bay Area public.

\section{Recurring Theme 3 - Negative Perception of Mental Health from Society}

(Number of Responses Aligning to Theme: 4)

This theme applies mainly to Question 2. It was the third most referenced theme throughout all responses and second to Theme 2 for Question 2. When asked for participant's initial thoughts on mental health and a brief debrief of their views on mental health today, many participants cited negative perception as the first thing that came to mind. Participant 26 had described the perception of mental health by noting a "lot of hostility and negativity" from the public towards this issue. Participant 23's response had also aligned with this view and said that "there is still a negative perception of mental disorders in the Bay Area."

From these responses, we can note that they all agree that the idea of a stigma associated with mental health persists today. Participants' initial thoughts on mental health in the Bay Area were associated with negative views from the public and a consensus against maintaining one's overall mental state.

\section{Conclusion}

Through this research, new data regarding mental health stigma pertaining to those in the Bay Area has been added to the existing body of knowledge regarding mental health. Before this study, previous studies on mental health had inadequately addressed mental health's stigma and its perception for the public, generally resulting in data specified to smaller specified populations. Additionally, past studies were generally not conducted in the Bay Area and failed to directly capture the views of their participants pertaining to mental health's stigma.

However, the findings of this study help to paint a better picture of what the consensus towards mental health is as well as its stigmatization in contemporary terms in the Bay Area.

From the results, we can note the changes in past perceptions to the contemporary perception of the stigmatization of mental health, specifically in the Bay Area for the public. The data collected from each participant provides detailed analysis and general commentary discussing current day programs as well as a consensus on their views of mental health through the themes developed.

Additionally, the data collected can provide new and valuable data for local health organizations with new methods of combat the issues pertaining to mental health care and public insight on the programs that are available today. The themes created can be used in the future to help health care providers determine what their patients place 
significance on during treatment. Existing health services could implement these suggestions given from the participants to tailor a better experience for patients and ultimately work towards the goal of reducing the rate of mental health disorders' occurrence.

With data collected from this study, there is a new understanding of what the public perception of mental health is today and the common themes in addressing these issues. Through this study, I was able to solidify my existing hypothesis about changing perceptions towards mental health for the public today. Compared to past studies, it seems like the Bay Area is moving away from stigmatizing mental health disorders and towards a more open discussion about these issues. Further research could implement these findings into new programs that could be used in universities or workplaces and have additional surveys conducted to see if there was any change in perception of mental health.

Moreover, the goal of future studies conducted would be then to get a bigger sample that is more representative of the Bay Area to provide another source to determine if the findings made in this study are correct. Researchers could potentially expand to other regions besides the Bay Area, focusing on different locations as well as other factors connected to mental health such as socio-economic inequalities and cultural bias.

\section{References}

Celine, T. M., \& Antony, J. (2014, January). A Study on Mental Disorders: 5-year Retrospective Study. Retrieved from http://www.ncbi.nlm.nih.gov/pmc/articles/PMC4005192/

Clark, W., Welch, S. N., Berry, S. H., Collentine, A. M., Collins, R., Lebron, D., \& Shearer, A. L. (2013). California's historic effort to reduce the stigma of mental illness: the Mental Health Services Act. American journal of public health, 103(5), 786-794. doi:10.2105/AJPH.2013.301225

Collins, R., Cerully, J., Wong, E., Golan, S., Yu, J., \& Filip-Crawford, G. (2014). Evaluating the California Mental Health Services Authority's Stigma and Discrimination Reduction Initiative: Year 1 Findings. In Evaluating the California Mental Health Services Authority's Stigma and Discrimination Reduction Initiative: Year 1 Findings. RAND Corporation. Retrieved January 15, 2020, from www.jstor.org/stable/10.7249/j.ctt5vjx39.1

Eunice C. Wong, Collins, R., Cerully, J., Roth, E., Marks, J., \& Jennifer Yu. (2015). Effects of Stigma and Discrimination Reduction Trainings Conducted Under the California Mental Health Services Authority: An Evaluation of the National Alliance on Mental Illness Adult Programs. In Effects of Stigma and Discrimination Reduction Trainings Conducted Under the California Mental Health Services Authority: An Evaluation of the National Alliance on Mental Illness Adult Programs (pp. 1-29). RAND Corporation. Retrieved from http://www.jstor.org/stable/10.7249/j.ctt19w7364.1

Gopalkrishnan N. (2018). Cultural Diversity and Mental Health: Considerations for Policy and Practice. Frontiers in public health, 6, 179. doi:10.3389/fpubh.2018.00179

Grøtan, K., Sund, E. R., \& Bjerkeset, O. (2019, January 24). Mental Health, Academic Self-Efficacy and Study Progress Among College Students - The SHoT Study, Norway. Retrieved from https://www.ncbi.nlm.nih.gov/pmc/articles/PMC6354661/

Heather Clark. (2017). “Imbalance:”: Mental Health in Higher Education. Humboldt Journal of Social Relations, 39 , 346-348. Retrieved from http://www.jstor.org/stable/90007891 
Holland, D. (2016). COLLEGE STUDENT STRESS AND MENTAL HEALTH: EXAMINATION OF STIGMATIC VIEWS ON MENTAL HEALTH COUNSELING. Michigan Sociological Review, 30, 16-43. Retrieved January 15, 2020, from www.jstor.org/stable/43940346

Major, B., \& Obrien, L. T. (2005). The Social Psychology of Stigma. Annual Review of Psychology, 56(1), 393-421. doi: 10.1146/annurev.psych.56.091103.070137

W. (2013, July 29). Mental disorders affect one in four people. Retrieved from https://www.who.int/whr/2001/media centre/press release/en/

Psychiatry, U.C.S.F. (2016, August 9). Eliminating stigma is key to effectively treating mental illness. Retrieved from https://psych.ucsf.edu/news/eliminating-stigma-key-effectively-treating-mental-illness

Wolf, J. (2018, January 23). Study shows stigma around mental health on campus correlates with students not seeking treatment. Retrieved from http://newsroom.ucla.edu/releases/study-shows-stigma-around-mental-health-on-campus-correlates-with-students-not-seeking-treatment 